\title{
Article \\ Effects of Elastic Band Plyometric Training on Physical Performance of Team Handball Players
}

\author{
Ghaith Aloui $^{1,+}{ }^{\dagger}$, Souhail Hermassi ${ }^{2, *,+} \mathbb{D}$, Lawrence D. Hayes ${ }^{3} \mathbb{D}$, Roy J. Shephard ${ }^{4}$, \\ Mohamed Souhaiel Chelly ${ }^{1, \ddagger(D)}$ and René Schwesig ${ }^{5, \ddagger(D)}$
}

1 Research Unit (UR17JS01) Sport Performance, Health \& Society, Higher Institute of Sport and Physical Education, Ksar-Saîd, University of "La Manouba”, Tunis 2010, Tunisia; gaithaloui@hotmail.fr (G.A.); mohamedsouhaiel.chelly@issep.uma.tn (M.S.C.)

2 Physical Education Department, College of Education, Qatar University, Doha 2713, Qatar

3 School of Health and Life Sciences, University of the West of Scotland, Glasgow G72 OLH, UK; Lawrence.Hayes@uws.ac.uk

4 Faculty of Kinesiology and Physical Education, University of Toronto, Toronto, ON 214, Canada; royjshep@shaw.ca

5 Department of Orthopaedic and Trauma Surgery, Martin-Luther-University Halle-Wittenberg, 06120 Halle, Germany; rene.schwesig@uk-halle.de

* Correspondence: shermassi@qu.edu.qa

+ The first two authors are co-first authors.

$\ddagger$ The last two authors are co-last authors.

\section{check for}

updates

Citation: Aloui, G.; Hermassi, S.; Hayes, L.D.; Shephard, R.J.; Chelly, M.S.; Schwesig, R. Effects of Elastic Band Plyometric Training on Physical Performance of Team Handball Players. Appl. Sci. 2021, 11, 1309. https://doi.org/10.3390/app11031309

Received: 8 January 2021

Accepted: 22 January 2021

Published: 1 February 2021

Publisher's Note: MDPI stays neutral with regard to jurisdictional claims in published maps and institutional affiliations.

Copyright: (c) 2021 by the authors Licensee MDPI, Basel, Switzerland. This article is an open access article distributed under the terms and conditions of the Creative Commons Attribution (CC BY) license (https:// creativecommons.org/licenses/by/ $4.0 /)$.
Featured Application: The elastic band presents a new material for plyometric training with loadlike weight machines, but it is less expensive and simple to implement. This kind of training is able to activate all relevant muscles and requires little time. Handball coaches should consider including in-season loaded plyometric training for upper limbs to improve handball performance.

Abstract: This project investigated the effect of incorporating 8 weeks of biweekly upper limb loaded plyometric training (using elastic bands) into the in-season regimen of handball players. Participants were randomly allocated to a control group (CG) $(n=15$, age $=18.1 \pm 0.5$ years, body mass $=73.7 \pm 13.9 \mathrm{~kg})$, or an experimental group $(\mathrm{EG})(n=14$, age $=17.7 \pm 0.3$ years, body mass $=76.8 \pm 10.7 \mathrm{~kg}$ ). The measurements obtained pre- and post-intervention included a cycle ergometer force-velocity test, ball throwing velocity in three types of throwing, one-repetition maximum (1-RM) bench press and pull-over, and anthropometric estimates of the upper limb muscle volumes. The EG improved in absolute muscle power $(\mathrm{W})(\Delta 23.3 \%$; interaction effect $p=0.032$ more than pre-intervention), relative muscle power $\left(\mathrm{W} \cdot \mathrm{kg}^{-1}\right)(\Delta 22.3 \%$; interaction effect $p=0.024)$, and all three types of ball throwing $(\Delta 18.6 \%$, interaction effect $p=0.019$ on a jumping shot; $\Delta 18.6 \%$, interaction effect $p=0.017$ on a three-step running throw; and $\Delta 19.1 \%$, interaction effect $p=0.046$ on a standing throw). There was no interaction effect for the 1-RM bench press and pull-over performance. The upper limb muscle volumes remained unchanged in both groups. We concluded that adding biweekly elastic band plyometric training to standard training improves the muscle power and throwing velocity. Accordingly, such exercises should be adopted as a part of a pragmatic approach to handball training.

Keywords: plyometric training; muscle power; load; team sports; throwing velocity; handball

\section{Introduction}

Handball is characterized by intermittent high-intensity efforts. Phases of low intensity alternate with phases of high activity [1,2]. Although the players spend the majority of a match's time at a lower intensity, most decisive actions, such as throwing, jumping, accelerating, sprinting, and tackles, demand high levels of explosiveness and strength [3-5]. 
Therefore, pragmatic conditioning programs should incorporate resistance training to promote these characteristics. Strength training is very diverse (e.g., plyometrics, isometrics, dynamics, and isokinetic training). In addition, other options are dynamic strength training combined with variable resistance such as elastics (also known as elastic bands, rubber bands, and tubing) [6-10] and weightlifting chains [11,12]. Plyometric training can be combined with variable resistance, such as that from a Smith machine $[13,14]$, and weighted vests $[15,16]$. There is much scientific evidence that dynamic strength training combined with elastic resistance is suitable for improving the strength performance of limbs in athletes $[6,16,17]$. The most pertinent feature of this training is the progressive increase in external resistance due to the instability of the band, which may induce a greater stimulus for strength adaptations [18] and a greater neuromuscular demand, improving motor unit recruitment and rate coding [19]. Another feature of elastic resistance is that, in addition to improving velocity, it increases the eccentric stimulus of training, which in turn increases the myoelectric activity of the relevant musculature [20].

Despite the efficacy of elastic resistance, no previous investigation has examined the effect of loaded plyometric training (elastic resistance) on game-specific performance. Plyometric training involves a muscle stretch prior to executing a rapid concentric contraction, termed the stretch shortening cycle (SSC) [21]. The inclusion of SSC in handball training is intuitively logical, as handball players often throw, push, jump, sprint, and change direction. Furthermore, several studies have shown improved athletic performance after loaded plyometric training using other types of resistance. Indeed, Lyttle et al. [13] noted an increase in one-repetition maximum (1RM) bench press and medicine ball throw performance following 8 weeks of biweekly loaded plyometric training (weighed bench press throw at 30\% 1RM) in adult male athletes. Moreover, Khalifa et al. [22] described improved jump performance after 10 weeks of loaded plyometric training (weight vest) in elite male basketball players. However, the equipment used for loaded plyometric training in these studies was more expensive, heavy, and sophisticated than elastic resistance, such as the elastic band, which is prohibitive for some athletes.

To the best of our knowledge, no previous research has investigated the effects of stressful plyometric training, using rubber bands with the relevant physical abilities of male handball players. The aim of this study was therefore to evaluate the effects of replacing normal training during the season with stressed plyometric training of the upper limbs in male junior handball players. The results examined were the maximum upper limb muscle strength, the maximum upper limb strength, the muscle volume, and the ball throwing speed. We hypothesized a priori that an 8 week program of elastic band plyometric training would increase the strength performance (upper limbs) and ball throwing velocity when compared with the control group (CG), who maintained their usual training during the season without adding rubber band plyometrics.

\section{Materials and Methods}

\subsection{Experimental Approach to the Problem}

Two familiarization sessions-2 weeks prior to testing and measurements began and 2 months after commencement of the competitive season-were conducted. Data were collected before and after the 8 weeks of added elastic band plyometric training. Pre- and postintervention measurements were performed at the same time of day (5:00 p.m.-7:00 p.m.) and under similar environmental conditions (temperature of $16-19^{\circ} \mathrm{C}$ ). Performance diagnostics were conducted at least 3 days after the last competitive match and 5-9 days after the previous training session. A standard warm-up was performed before maximal efforts. Anthropometric assessment was followed by the force-velocity test on the first day. On the second day, an assessment of ball throwing velocity was conducted. Determination of the one-repetition maximum pull-over (1RMPO) and 1RM bench press (1RMBP) was completed on the third and final testing day. The subjects maintained their habitual intake of food and fluids according to self-reporting and abstained from physical exercise for 1 day. They should not have drunk beverages containing caffeine for $4 \mathrm{~h}$ and should have arrived 
for testing $>2 \mathrm{~h}$ postprandial. All players were verbally encouraged to give maximal effort throughout the tests.

\subsection{Subjects}

Twenty-nine junior team handball players (age $=17.7 \pm 0.4$ years, body mass $=75.7 \pm 16.2 \mathrm{~kg}$, height $=1.81 \pm 0.06 \mathrm{~m}$, body fat $=14.1 \pm 4.9 \%$ ) from a national handball team in the first division participated (experience of handball competition $=6.3 \pm 0.8$ years). Prior to participation, participants were examined by the team physician to ensure the participants did not present conditions that would preclude elastic band plyometric training. All participants were found to be of good well-being and in good health. The players were characterized by playing position and were then subsequently and randomly allocated to either the experimental group (EG) or the CG. The groups were matched in terms of baseline characteristics (EG age $=17.7 \pm 0.3$ years, height $=1.83 \pm 0.04 \mathrm{~m}$, body mass $=76.8 \pm 10.7 \mathrm{~kg}$, body fat $=13.4 \pm 3.8 \%$; CG age $=18.1 \pm 0.5$ years, height $=$ $1.82 \pm 0.06 \mathrm{~m}$, body mass $=73.7 \pm 13.9 \mathrm{~kg}$, body fat $=14.4 \pm 6.0 \%$ ). No significant group differences for anthropometric characteristics were observed (significance level $=p \leq 0.05$ ).

The habitual regimen for participants included Tuesday sessions of moderate resistance training (overhead lunges, pull-ups, push-ups, body weight squats, and jump squats) plus light resistance training (40-60\% 1RM exercises such as pull-overs, bench presses, and half back squats) and Thursday sessions of tactical and technical training. For 8 weeks, the EG replaced their standard regimen with the loaded plyometric training.

\subsection{Testing Schedule}

\subsubsection{Day 1}

Anthropometry

The skinfolds were determined using a Harpenden caliper (Baty International, Burgess Hill, Sussex, UK). The upper limb muscle volume was estimated as previously described in [4], using skinfold thicknesses and circumferences measured at several points on the arm, arm length, and humeral condyle breadth:

$$
\text { Muscle volume }=\text { total limb volume }-(\text { fat volume }+ \text { bone volume })
$$

The limb volume was determined as a cylindrical volume based on its length (L), distance from acromion process to the smallest wrist circumference, and mean of five limb circumferences (axilla, maximum relaxed biceps, minimum above the elbow, maximum over the relaxed forearm, and minimum above the styloid process):

$$
\text { Total limb volume }=\left(\sum \mathrm{C} 2\right) / \mathrm{L} / 62.8
$$

where $\mathrm{C} 2$ is the square of the five circumferences. The fat volume was calculated as

$$
\left(\sum \mathrm{C} / 5\right) \cdot\left[\left(\sum \mathrm{S} / 2 \mathrm{n}\right)\right] \mathrm{L}
$$

where $\mathrm{S}$ is three skinfolds of the upper limb (biceps, triceps, and mid-forearm) and $\mathrm{n}$ is the number of skinfolds taken on each limb. The bone volume was calculated thusly:

$$
\pi \text {. (F . D) } 2 \text {. L }
$$

where $\mathrm{D}$ is the diameter of the humeral intercondylar area, $\mathrm{F}$ is a geometric factor ( 0.21 for the upper limb), and $\mathrm{L}$ is the limb length measured previously. The body fat percentage was determined using the four-site Durnin and Wormerseley method [23].

\section{Force-Velocity Test}

The upper limb force-velocity measurement was tested on a standard Monark cycle ergometer (model 894 E, Monark Exercise AB, Vansbro, Sweden) as detailed previously in [4]. Briefly, the instantaneous maximum cadence during a $7 \mathrm{~s}$ sprint was integrated 
to calculate the maximal power for a given braking force. We considered participants as having reached peak power (Wpeak) when increasing the load resulted in a decreased power output. The parameters obtained were the Wpeak, maximal cadence (V0), and maximal braking force (F0). The test began with a braking force equating to $1.5 \%$ of the body mass [4]. After $5 \mathrm{~min}$ of recovery, the resistance was sequentially increased to 2, 3, 4, $5,6,7,8$, and $9 \%$ of the participant's body mass.

\subsubsection{Day 2}

Ball Throwing

On an indoor handball court, three types of overarm throwing were performed specific to team handball: a standing (penalty) throw, a three-step running throw, and a jump throw, as previously described in [24]. These throws were recorded on a digital video camera (Sony Handycam DCR-SD1000, Tokyo, Japan) with a frame rate of $25 \mathrm{~Hz}$ on a tripod $1.5 \mathrm{~m}$ above the ground and sagittal to the player. Ball displacement-time data were converted to velocities (Regavi and Regressi, Micrelec, Coulommiers, France). Validity of the camera and data processing software was assessed by measuring the speeds of rolling balls $\left(2-14 \mathrm{~m} \cdot \mathrm{s}^{-1}\right)$ by the camera $(\mathrm{Vc})$ and checking them over a $3 \mathrm{~m}$ distance using photoelectric cells $(\mathrm{Vpc})$ (GLOBUSREHAB and Sports High Tech, Articolo ERGO TIMER, Italy) [24]. The linear relationship between the two velocity measures $\left(\mathrm{V}_{\mathrm{c}}=0.99363 \mathrm{Vpc}+0.65\right)$ showed they were strongly correlated $(\mathrm{r}=0.99)$ [24].

\subsubsection{Day 3}

One-Repetition Maximum Strength Testing

For the maximal pull-over, the barbell was positioned $20 \mathrm{~cm}$ above the chest, supported by the bottom stops of the device, while the participants were laying supine. The participants performed consecutive eccentric-concentric contractions from the starting position, whereby the eccentric action took the weight over and posterior to the head. The elbows were fully extended, and the concentric action returned the barbell to its starting position with extended elbows. The participants were familiarized with the desired technique, having regularly trained using pull-overs in their habitual weekly training sessions. A pre-test estimate of the 1RMPO was made during the final standard training session and, for the $1 \mathrm{RMPO}$, as for the $1 \mathrm{RMBP}$, five repetitions at $40-60 \%$ of the pre-test were completed as a warm-up. Thereafter, $4-5$ attempts, interspersed by 2 min of recovery, were performed until the participant was unable to extend their arms fully on two occasions. The last acceptable extension (similar to the starting position) was considered to be the 1RMPO performance $(\mathrm{kg})$.

As previously described in detail in [4], the 1RMBP was performed in a Smith machine with the barbell attached at both distal ends and on the two vertical bars' linear bearings, ensuring only vertical displacement. The participants lay supine, and the barbell was positioned above the chest ( $\sim 30 \mathrm{~cm}$ from the ground), supported by the bottom stops on the device. Successive elbow flexions and extensions were completed from the starting position, with arching of the back and bouncing being forbidden.

\section{Loaded Plyometric Training (Elastic Band) Program}

The subjects did not complete any training outside of the handball team throughout the study's duration. Each Tuesday and Thursday for 8 weeks, the experimental group substituted part of the standard regime (the technical-tactical part) with elastic band plyometric training (Table 1). The elastic band (Thera-Bands ${ }^{\circledR}$; Hygenic Corporation; Akron, Ohio, USA) system included two latex bands of differing elasticities: black (special heavy) and silver (super heavy). The subjects performed exercises with maximal effort (maximal concentric velocity). The loaded plyometric program comprised two exercises: plyometric standard push-ups (Figure 1) and plyometric diamond and wide arm push-ups (Figure 2). Training sessions began with a $15 \mathrm{~min}$ warm-up and lasted for $20 \mathrm{~min}$ (a total of $35 \mathrm{~min}$ ). 
Table 1. Details of loaded the plyometric (elastic band) training program performed by the experimental group over the 8 week trial.

\begin{tabular}{|c|c|c|c|c|c|c|c|c|}
\hline Exercises & Session 1 & Session 2 & Session 3 & Session 4 & Session 5 & Session 6 & Session 7 & Session 8 \\
\hline & \multicolumn{4}{|c|}{ With 2 black elastic bands at $150 \%$ elongation (11.2 kg) } & \multicolumn{4}{|c|}{ With 2 silver elastic bands at $150 \%$ elongation $(15.6 \mathrm{~kg})$} \\
\hline \multirow{2}{*}{$\begin{array}{c}\text { Plyometric Standard Push-up } \\
\text { Plyometric Diamond and Wide } \\
\text { Arm Push-up }\end{array}$} & $4 \times 6$ & $4 \times 6$ & $5 \times 6$ & $5 \times 6$ & $4 \times 6$ & $4 \times 6$ & $5 \times 6$ & $5 \times 6$ \\
\hline & $4 \times 6$ & $4 \times 6$ & $5 \times 6$ & $5 \times 6$ & $4 \times 6$ & $4 \times 6$ & $5 \times 6$ & $5 \times 6$ \\
\hline \multirow[t]{2}{*}{ Exercises } & Session 9 & Session 10 & Session 11 & Session 12 & Session 13 & Session 14 & Session 15 & Session 16 \\
\hline & \multicolumn{4}{|c|}{$\begin{array}{l}\text { With } 2 \text { silver plus } 1 \text { black elastic bands at } 150 \% \text { elongation } \\
\qquad(21.2 \mathrm{~kg})\end{array}$} & \multicolumn{4}{|c|}{$\begin{array}{l}\text { With } 2 \text { silver plus } 2 \text { black elastic bands at } 150 \% \text { elongation } \\
\qquad(26.8 \mathrm{~kg})\end{array}$} \\
\hline \multirow{2}{*}{$\begin{array}{l}\text { Plyometric Standard Push-up } \\
\text { Plyometric Diamond and Wide } \\
\text { Arm Push-up }\end{array}$} & $4 \times 6$ & $4 \times 6$ & $5 \times 6$ & $5 \times 6$ & $4 \times 6$ & $4 \times 6$ & $5 \times 6$ & $5 \times 6$ \\
\hline & $4 \times 6$ & $4 \times 6$ & $5 \times 6$ & $5 \times 6$ & $4 \times 6$ & $4 \times 6$ & $5 \times 6$ & $5 \times 6$ \\
\hline
\end{tabular}

(sets $\times$ repetitions).

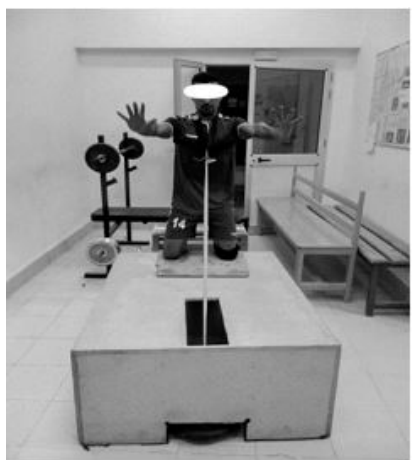

A. Starting position of plyometric standard push-up

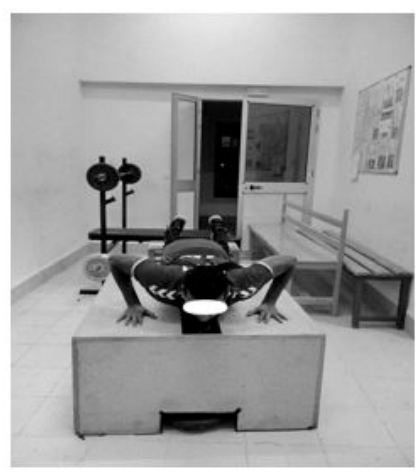

B. Reception phase of plyometric standard push-up

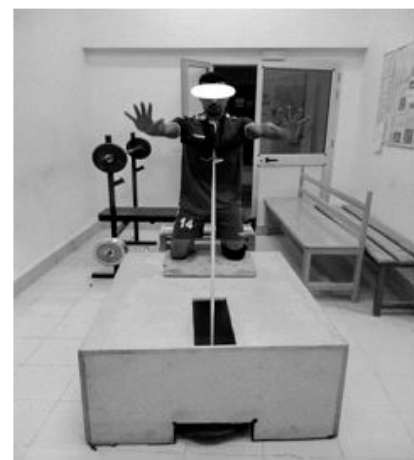

C. Final position of plyometric standard push-up

Figure 1. Phases of plyometric standard training exercise.

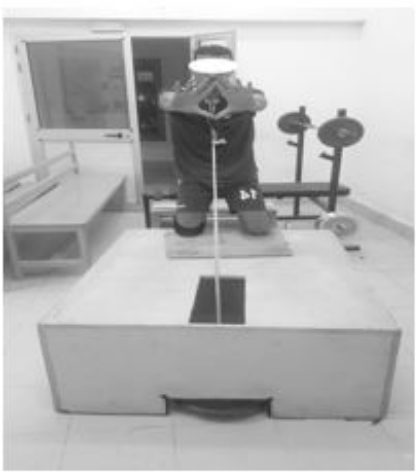

A. Starting position of plyometric diamond push-up

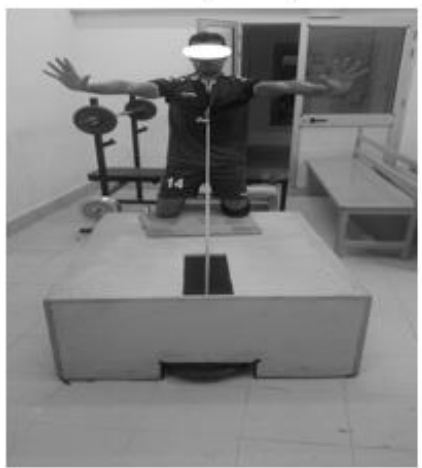

D. Starting position of plyometric wide arm push-up

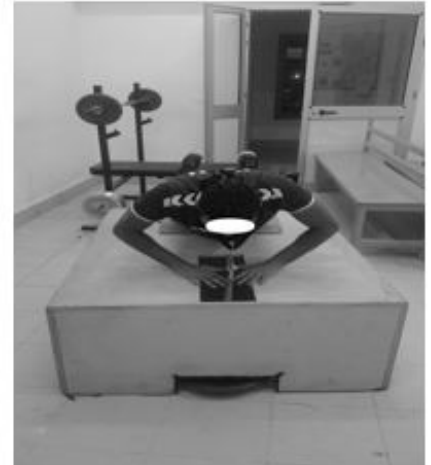

B. Reception phase of plyometric diamond push-up

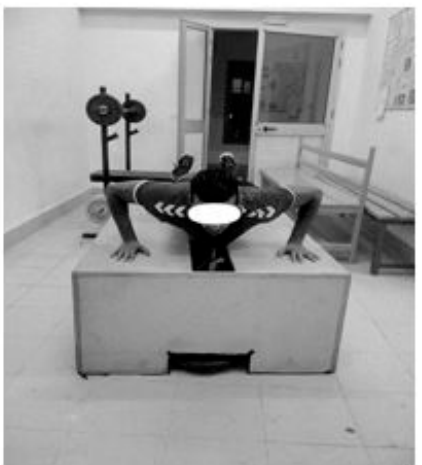

E. Reception phase of plyometric wide arm push-up

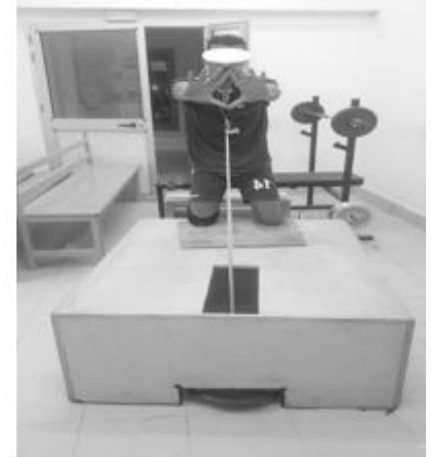

C. Final position of plyometric diamond push-up

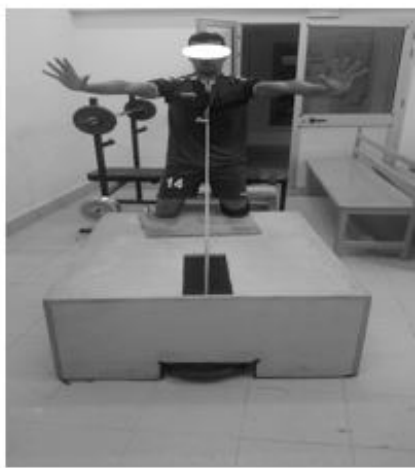

F. Final position of plyometric wide arm push-up

Figure 2. Phases of plyometric diamond and wide arm push-up training exercise. 
A battery of warm-up exercises preceded plyometric training (e.g., exercises regarding running, coordination, trunk rotation, flexibility, jumping, and sprinting). Internal and external rotary, flexion, and extension movements of the shoulders, normal and plyometric push-ups with both hands on the ground, 8-10 free medicine ball throws, and 8-10 free ball throws were also performed. Two black elastic bands, two silver elastic bands, two silver plus one black elastic bands, and two silver plus two black elastic bands were used for the first and second weeks, the third and fourth weeks, the sixth and seventh weeks, and the seventh and twelfth weeks, respectively, to ensure progression.

For both exercises, the knees and feet remained in contact with the top of a wooden box which participants exercised upon (height of $50 \mathrm{~cm}$, length of $120 \mathrm{~cm}$, and a width of $90 \mathrm{~cm}$ ). The elastic band was attached to the chest (upper part of the sternum) via a strap and vertically through a rectangular hole in the wooden box (opening $30 \mathrm{~cm}$ long and $15 \mathrm{~cm}$ wide). The hole in the box was in front of and parallel to the subjects' chests when in a standard push-up position. The initial elastic band length was $\sim 35 \mathrm{~cm}$ for both exercises and $\sim 90 \mathrm{~cm}$ when participants were in the initial push-up position.

\section{Plyometric Standard Push-Up}

The subjects were kneeling, with the trunk vertical, knees and feet remaining in contact with the floor, shoulders in antepulsion $\left(90^{\circ}\right)$, elbows extended, and palms facing forward. The participants fell forward (under the effect of gravity), extending their arms forward with a slight elbow flexion to prepare for contact with the box, stopping the movement at approximately a $90^{\circ}$ elbow flexion. Participants immediately extended their arms rapidly, propelling the upper body as high as possible toward the starting position. The subjects then initiated the next push-up immediately (i.e., no pause between repetitions) and continued until the prescribed number of repetitions was complete.

\section{Plyometric Diamond and Wide Arm Push-Up}

These exercises were completed in a similar fashion to the plyometric standard pushup, except that in the diamond push-up, the participants' hands were together, with the thumbs and index fingers touching to form a diamond shape. For the wide arm push-ups, the hands were held at approximately double the shoulder width apart. The elastic band plyometric training began with a resistance of $11.2 \mathrm{~kg}$, with an increase of 4-5 kg every four sessions to reach a final resistance of $26.8 \mathrm{~kg}$, and the resistance was derived from the manufacturer's manual, based on the elongation of the band. The number of sets was increased every two sessions (from four to five sets) for each resistance level. The number of repetitions per set was maintained at six repetitions. No injuries were reported over the 16 workouts.

\subsection{Statistical Analyses}

Statistical analyses were conducted using SPSS version 25.0 for Windows (IBM, Armonk, NY, USA). Normality was tested using the Kolmogorov-Smirnov test, and Levene's test determined the homogeneity of variance. Independent $t$-tests examined differences between the groups at the baseline. Training-related effects were assessed by two-way (group $\times$ time) repeated measures analyses of variance (ANOVAs). Subsequently, Tukey's post hoc correction was applied to locate pair-wise differences. Analysis of covariance (ANCOVA) was conducted for variables with baseline differences between groups. The effect size was calculated using Cohen's $d$, and it was classified as trivial $(d<0.2)$, small $(0.2 \leq d \leq 0.6)$, moderate $(0.6 \leq d \leq 1.2)$, large $(1.2 \leq d \leq 2.0)$, or very large $(d>2.0)$ [25] The reliability of these measures was assessed using intraclass correlation coefficients (ICCs) [26] and the coefficients of variation (CVs) over consecutive pairs of intrasubject trials [10]. An ICC of more than 0.90 was considered as a high reliability, between 0.80 and 0.90 was a moderate reliability, and less than 0.80 was an insufficient reliability for physiological field tests [26]. The alpha level was reported as exact $p$ values, as suggested by Hurlbert et al. [27]. Data were reported as means \pm standard deviation (SD). 


\section{Results}

Three types of throwing velocities showed an ICC $>0.80$ and a CV $<5 \%$ (Table 2).

Table 2. Intraclass correlation coefficient and coefficient of variation showing acceptable reliability for measures of ball throwing velocities.

\begin{tabular}{cccc}
\hline & ICC & $\mathbf{9 5 \%} \mathbf{C I}$ & CV (\%) \\
\hline Ball Throwing Velocity $\left(\mathbf{m} \cdot \mathbf{s}^{-\mathbf{1}}\right)$ & & & \\
Jumping throw & 0.96 & $0.91-0.98$ & 3.1 \\
Three-step running throw & 0.95 & $0.89-0.98$ & 3.2 \\
$\quad$ Standing throw & 0.96 & $0.91-0.98$ & 3.6 \\
\hline ICC $=$ intraclass correlation coefficient $\cdot \mathrm{CI}=$ confidence interval $\cdot \mathrm{CV}=$ coefficient of variation.
\end{tabular}

$\overline{\mathrm{ICC}}=$ intraclass correlation coefficient; $\mathrm{CI}=$ confidence interval; $\mathrm{CV}=$ coefficient of variation.

Based on the first examination, we performed a factor analysis to reduce the dimensions (clustering of parameters) and to determine the total variance explained by the test parameters. In this context, the test parameters were subjected to a factor analysis (extraction method: principal component analysis; rotation method: varimax with Kaiser normalization), with only intrinsic values greater than one being included in the analysis.

In the first step, we identified two factors that explained $70 \%$ of the total variance of the physical performance construct (first factor: $45 \%$; second factor: $25 \%$ ).

In the second step, we were able to assign the parameters to the following factors:

\begin{tabular}{ll}
\hline 1. Force and Throw: & Arm Muscle Volume, Standing Throw, Running Throw, Jumping \\
& Throw, $1 \mathrm{RM}$ Bench Press, 1RM Pull-Over
\end{tabular}

2. Power and Velocity: Body Fat, Warm.peak, V0, F0

In the third step, we performed a separate factor analysis of the identified factors to identify the following explained variance: factor 1 (force and throw): $74 \%$; factor 2 (power and velocity): $57 \%$.

\subsection{Effect of Training on Anthropometric Measures}

No significant interaction effect (i.e., group $\times$ time) was present in the anthropometric measures (Table 3). However, the paired sample $t$-tests indicated an improvement in arm muscle volumes $(\mathrm{L})(\Delta 13.8 \%$; $t$-test $p=0.001 ; d=0.619)$ in the EG. All other anthropometric changes were not relevant.

\subsection{Effect of Training on Power Performance}

For the force-velocity test, a group $\times$ time interaction existed at the $p<0.05$ level for the peak power $(\mathrm{W})$ and relative peak power $\left(\mathrm{W} \cdot \mathrm{kg}^{-1}\right)$. No interaction effect was noted for the muscle quality $\left(\mathrm{W} \cdot \mathrm{L}^{-1}\right)$, peak cadence $(\mathrm{rpm})$, or peak force $(\mathrm{N})$. In terms of magnitude, the experimental group experienced a large increase in the absolute peak power and relative peak power, as well as a moderate increase in muscle quality and peak cadence. A small improvement was noted in the peak force (Table 4).

\subsection{Effect of Training on Maximum Muscular Strength Performance}

No interaction effect at the $p<0.05$ level was observed in the ANOVA of the 1RMPO or 1 RMBP. In post hoc analyses, the experimental group experienced a large improvement in the 1RMPO, while the control group experienced a moderate improvement. In regard to the bench press, the experimental group experienced a moderate improvement in performance, while the control group experience a trivial improvement (Table 5). 
Table 3. Comparison of muscle volume of the arm and body fat percentage between the experimental and control groups before and after an 8 week intervention.

\begin{tabular}{|c|c|c|c|c|c|c|c|c|c|c|c|c|}
\hline & \multicolumn{3}{|c|}{ Experimental $(\mathrm{n}=14)$} & \multicolumn{2}{|c|}{ Paired $t$-Test } & \multicolumn{3}{|c|}{ Control $(n=15)$} & \multicolumn{2}{|c|}{ Paired $t$-Test } & \multicolumn{2}{|c|}{ ANOVA (Group $x$ Time) } \\
\hline & Pre & Post & $\% \Delta$ & $p$ & $d$ (Cohen) & Pre & Post & $\% \Delta$ & $p$ & $d$ (Cohen) & $p$ & $d$ (Cohen) \\
\hline Arm muscle volume (l) & $3.5 \pm 0.74$ & $4.0 \pm 0.73$ & $13.8 \pm 11.5$ & 0.001 & 0.62 & $3.7 \pm 0.55$ & $3.8 \pm 0.60$ & $2.4 \pm 5.6$ & 0.141 & 0.16 & 0.293 & 0.02 (small) \\
\hline Body fat $\%$ & $13.4 \pm 3.8$ & $13.2 \pm 3.5$ & $-0.5 \pm 8.4$ & 0.562 & 0.05 & $14.4 \pm 6.0$ & $14.6 \pm 5.8$ & $0.17 \pm 5.0$ & 0.260 & 0.03 & 0.899 & 0.06 (small) \\
\hline
\end{tabular}

Table 4. Force-velocity test data for the upper limbs for the experimental and control groups before and after an 8 week intervention.

\begin{tabular}{|c|c|c|c|c|c|c|c|c|c|c|c|c|}
\hline & \multicolumn{3}{|c|}{ Experimental $(\mathrm{n}=14)$} & \multicolumn{2}{|c|}{ Paired $t$-Test } & \multicolumn{3}{|c|}{ Control $(\mathrm{n}=15)$} & \multicolumn{2}{|c|}{ Paired $t$-Test } & \multicolumn{2}{|c|}{ ANOVA (Group x Time) } \\
\hline & Pre & Post & $\% \Delta$ & $p$ & $d$ (Cohen) & Pre & Post & $\% \Delta$ & $p$ & D (Cohen) & $p$ & $d$ (Cohen) \\
\hline Warm.peak $_{\text {.W }}$ & $416 \pm 60$ & $511 \pm 72 *$ & $23.3 \pm 3.6$ & 0.001 & 1.45 & $405 \pm 51$ & $433 \pm 52$ & $7.1 \pm 10.0$ & 0.016 & 0.53 & 0.032 & 0.08 (small) \\
\hline Warm.peak $\left(\mathrm{W} \cdot \mathrm{k}^{-1}\right)$ & $5.6 \pm 0.52$ & $6.9 \pm 0.73 *$ & $22.3 \pm 4.1$ & 0.001 & 1.99 & $5.3 \pm 1.1$ & $5.4 \pm 1.2$ & $2.6 \pm 11.6$ & 0.461 & 0.10 & 0.024 & 0.09 (small) \\
\hline Warm.peak $(\mathrm{W} / \mathrm{L})$ & $119 \pm 12$ & $130 \pm 18$ & $9.3 \pm 10.6$ & 0.006 & 0.72 & $110 \pm 16$ & $115 \pm 18$ & $5.2 \pm 14.0$ & 0.146 & 0.30 & 0.488 & 0.01 (small) \\
\hline V0 (rpm) & $135 \pm 11$ & $142 \pm 11$ & $4.9 \pm 1.5$ & 0.001 & 0.61 & $138 \pm 13$ & $141 \pm 14$ & $2.8 \pm 4.9$ & 0.046 & 0.27 & 0.660 & 0.00 (small) \\
\hline F0 $(\mathrm{N})$ & $111 \pm 17$ & $119 \pm 18$ & $6.8 \pm 1.3$ & 0.001 & 0.44 & $114 \pm 24$ & $116 \pm 23$ & $3.0 \pm 13.9$ & 0.720 & 0.08 & 0.609 & 0.01 (small) \\
\hline
\end{tabular}

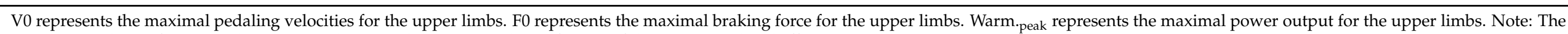
two-way analysis of variance (group $x$ time) assessed the statistical significance of the training-related effects; ${ }^{*} p \leq 0.05$.

Table 5. Comparison of ball throwing velocities and 1RM strength of the upper limbs for the experimental and control groups before and after an 8 week intervention.

\begin{tabular}{|c|c|c|c|c|c|c|c|c|c|c|c|c|}
\hline & \multicolumn{3}{|c|}{ Experimental $(\mathrm{n}=14)$} & \multicolumn{2}{|c|}{ Paired $t$-Test } & \multicolumn{3}{|c|}{ Control $(n=15)$} & \multicolumn{2}{|c|}{ Paired $t$-Test } & \multicolumn{2}{|c|}{$\begin{array}{l}\text { ANOVA (Group } x \\
\text { Time) }\end{array}$} \\
\hline & Pre & Post & $\% \Delta$ & $p$ & $d$ (Cohen) & Pre & Post & $\% \Delta$ & $p$ & $d$ (Cohen) & $p$ & $d$ (Cohen) \\
\hline \multicolumn{13}{|c|}{ Ball Throwing Velocities (m.s ${ }^{-1}$ ) } \\
\hline Jumping throw & $22.4 \pm 2.4$ & $26.5 \pm 2.7^{*}$ & $18.6 \pm 2.0$ & 0.001 & 1.61 & $21.7 \pm 2.6$ & $22.5 \pm 2.8$ & $3.8 \pm 5.2$ & 0.012 & 0.32 & 0.019 & 0.10 (small) \\
\hline Three-step running throw & $23.0 \pm 1.9$ & $27.4 \pm 2.0 *$ & $19.1 \pm 3.3$ & 0.001 & 2.23 & $22.1 \pm 2.8$ & $23.1 \pm 3.2$ & $4.8 \pm 6.0$ & 0.001 & 0.37 & 0.017 & 0.10 (small) \\
\hline Standing throw & $21.6 \pm 2.6$ & $26.0 \pm 3.1 *$ & $20.4 \pm 2.1$ & 0.001 & 1.53 & $20.7 \pm 2.8$ & $22.0 \pm 2.9$ & $6.4 \pm 9.1$ & 0.001 & 1.53 & 0.046 & 0.07 (small) \\
\hline \multicolumn{13}{|c|}{1 RM Strength (kg) } \\
\hline 1RM bench press & $73.4 \pm 14$ & $85.0 \pm 17$ & $15.9 \pm 1.1$ & 0.001 & 0.97 & $72.4 \pm 16$ & $75.2 \pm 18$ & $3.7 \pm 4.9$ & 0.001 & 0.17 & 0.303 & 0.02 (small) \\
\hline
\end{tabular}

Note: A two-way analysis of variance (group $\mathrm{x}$ time) assessed the statistical significance of the training-related effects; ${ }^{*} p \leq 0$. 


\subsection{Effect of Training on Throwing Performance}

Significant interaction effects were observed in the jumping throw, the three-step running throw, and the standing throw. In post hoc analyses, the EG experienced a very large improvement in the three-step running throw and large improvements in the jumping throw and standing throw. The CG experienced a small improvement in the three-step running throw and jumping throw and a large improvement in the standing throw (Table 5).

\section{Discussion}

The aim of this study was to evaluate the effectiveness of an 8 week plyometric exercise program for elastic bands for improving the muscle performance and ball throwing speeds in elite youth handball players. The data presented here suggest that replacing some aspects of typical training with elastic band upper body plyometric training produces moderate to large improvements in the muscle power of the upper limbs without meaningfully altering anthropometrics. Moreover, and possibly more pertinent to coaches and practitioners, large to very large improvements were noted in ball throwing velocities, which would likely improve sport-specific performance.

\subsection{Effect of Training on Power Performance}

The EG showed improvements in muscle performance in the upper limbs, although there was no significant change if the power was expressed per liter of muscle volume (i.e., muscle quality). Previous investigations concerning plyometric training [28] or resistance training [29-31] saw improvements in both the absolute and relative power of the lower limbs. No changes were calculated if power was expressed per liter of muscle volume in elite male handball players. Chelly et al. [28] reported a gain in absolute (27\%) and relative (28\%) upper limb power during a force-velocity test following plyometric training without an added load in elite players. In addition, Hermassi et al. [30] noted improved absolute $(12 \%)$ and relative $(11 \%)$ upper limb power during force-velocity testing after resistance training in elite male handball players. Mechanisms explaining the increased absolute power in the present study and the studies discussed here could be explained by an increased myofiber length (number of sarcomeres in a series) [32]. Moreover, plyometric training induces neuromuscular adaptation (e.g., increased motor unit recruitment, rate coding, synchronization, and intermuscular coordination [33-35]) that may have contributed to increased power production $[33,36]$.

\subsection{Effect of Training on Anthropometric Measures}

The current study showed only a moderate change in upper limb muscle volumes in the EG, implying the large increase in muscle power was driven primarily by neural adaptations described in the previous paragraph rather than muscular hypertrophy. This is encouraging for the practitioner, as the increasing power output-in the absence of body mass increases-improves the power-to-mass ratio and may enhance other attributes such as jumping, change of direction, and sprinting, whereby individuals are required to accelerate their own body mass. However, whether improvements in upper and lower body power in the current study translate to improvements in sprinting or jumping requires further investigation.

\subsection{Effect of Training on Maximum Muscular Strength Performance}

Performance in team handball depends not only on strength, but also on the ability to generate force at a high speed [30]. Powerful actions are associated with high-velocity movements (e.g., in jumping, sprinting, and throwing) [37]. The current study showed moderate to large improvements in strength performance in the EG, measured by bench presses $(16 \%)$ and pull-overs $(23 \%)$. The improvements we observed were in line with those reported by Lyttle et al. [13], who observed an improved 1RM bench press (13\%) after 8 weeks of biweekly loaded plyometric training (weighed bench press throw at 30\% 
1RM) in adult male athletes. However, a recent study [38] reported greater improvements in upper body strength (68\% and $27 \%$ for the bench press and pull-over, respectively) than those observed in our study after 10 weeks of biweekly resistance-based circuit training. Differences in acute program variables (duration, frequency, intensity, and type of exercise) and methodology (competitive level of players, age of players, and duration of studies) could contribute to divergences between the studies. However, it is clear that a combination of resistance training, handball technique, and competitive skills training enhances the maximal muscular strength and power production of the upper limbs, giving players an advantage in actions such as throwing $[4,28,39]$.

\subsection{Effect of Training on Maximum Ball Throwing Performance}

This study is the first to examine the effect of elastic band plyometric training on throwing performance in junior handball players. The throwing velocity is of paramount importance for high-caliber match performance. It is known that elite handball players exhibit substantially greater throwing ball velocities than lower-level competitors (8-9\% advantage in men [40] and 10-11\% advantage in women [41]). We observed improved ball velocities in the EG compared with the CG in all three types of ball throwing. The velocity of the jumping shot was increased by $19 \%$ (EG) and $4 \%$ (CG). Similarly, the velocity of the three-step running throw was improved by 19\% (EG) and 5\% (CG). Analogously, the velocity of the standing throw increased by $20 \%$ (EG) and $6 \%$ (CG). These results are in accordance with Chelly et al. [28], who noted enhanced throwing velocities (29\% for the jumping throw, $22 \%$ for the three-step running throw, and $19 \%$ for the standing throw) following 8 weeks of biweekly lower and upper limb plyometric training without an added load (plyometric push-ups). Similarly, Mascarin et al. [42] noted increased ball throwing velocities (6\% for the standing throw and $8 \%$ for the jumping throw) in young female players after 6 weeks of triweekly dynamic elastic band training for the shoulder. Additionally, Hermassi et al. [29] reported improved handball throwing velocities (43\% for the three-step running throw after heavy loaded resistance training and $38 \%$ for the three-step running throw after moderate loaded resistance training) following 8 weeks of upper limb resistance training. It is evident from the date presented here and studies similar in outcome that training with a focus on enhancing muscle power can enhance handball throwing velocities. To this end, Chelly et al. [43] reported that the peak power of both the upper and lower limbs were closely correlated with the throwing velocity. Differences in the magnitude of improvement were likely because of differences in study design, measurement methods (photoelectric cells, radar, or cinematography), throwing techniques (standing throw, three-step running throw, and jumping throw) [28,39], competition level (amateur or professional), type of training, intensity, and the age of the players.

\subsection{Practical Applications and Limitations}

This controlled study showed that 8 weeks of biweekly in-season upper limb loaded plyometric training enhanced the peak power outputs and throwing velocities in team handball players. Thus, it appears pragmatic to incorporate this form of plyometric training into traditional in-season tactical and technical handball training sessions to enhance handball match performance. The elastic band presents a new material for plyometric training with an external load like in weight machines, but it is less expensive and simple to implement. It also activates all relevant muscle groups (upper and lower limbs) and requires little allocation of time. Current results indicate that fitness and handball coaches should consider including in-season loaded plyometric training for the upper limbs to enhance the performance of their players. It remains to be seen how much plyometric training with an added load adds to other intervention training methods, such as heavy resistance training. Moreover, the neuromuscular mechanisms which underpin the improvements reported herein may also be an area for future research. This study is primarily applicable to one particular category of elite junior players. Future studies should evaluate and extend these findings to female players, other age groups, and other competition levels. There is 
also a need to compare the gains in the test performances with the actual improvement of play on the handball field. In addition, having a control group perform the plyometric push-up program without elastic bands would allow for the determination of whether the addition of bands is beneficial for this type of program versus performing unloaded upper extremity plyometrics training. It is possible that performing the plyometric push-up program without elastic bands may lead to comparable improvements. Furthermore, the use of force transducers within the elastic bands can improve the biomechanical understanding of the contribution of the elastic resistance to the push-up exercises. Alternatively, subjects could perform the push-ups on a force platform, thus giving a kinetic comparison between exercises performed with and without elastic resistance.

\section{Conclusions}

In conclusion, adding elastic band plyometric training to standard training improves muscle performance and ball throwing velocities without significantly altering muscle mass, suggesting the improvements were neurally dependent. Therefore, handball coaches and practitioners should incorporate elastic band plyometric training into handball training as a pragmatic approach to enhance specific and non-specific fitness.

Author Contributions: Conceptualization, G.A., R.J.S., and S.H.; methodology, G.A.; software, M.S.C.; validation, G.A., M.S.C., and S.H.; formal analysis, M.S.C.; investigation, G.A.; resources, G.A.; data curation, M.S.C.; writing-original draft preparation, S.H., G.A., and L.D.H.; writing-review and editing, L.D.H., and R.J.S.; visualization, M.S.C.; supervision, S.H.; project administration, G.A.; funding acquisition, R.S. All authors have read and agreed to the published version of the manuscript.

Funding: The authors thank the Ministry of Higher Education and Scientific Research, Tunis, Tunisia for financial support.

Institutional Review Board Statement: The study was conducted according to the guidelines of the Declaration of Helsinki and approved by the institutional review board of Research Unit (UR17JS0110.09.2019) Sport Performance, Health \& Society, Higher Institute of Sport and Physical Education, Ksar-Saîd, University.

Informed Consent Statement: Informed consent was obtained from all subjects involved in the study.

Data Availability Statement: The raw data supporting the conclusions of this article will be made available by the authors without undue reservation.

Acknowledgments: The authors thank the "Ministry of Higher Education and Scientific Research, Tunis, Tunisia" for financial support.

Conflicts of Interest: The authors declare no conflict of interest.

\section{References}

1. Chelly, M.S.; Hermassi, S.; Aouadi, R.; Shephard, R.J. Effects of 8-week in-season plyometric training on upper and lower limb performance of elite adolescent handball players. J. Strength Cond. Res. 2014, 28, 1401-1410. [CrossRef]

2. Povoas, S.; Seabra, A.; Ascensao, A.; Magalhaes, J.; Soares, J.; Rebelo, A. Physical and physiological demands of elite team handball. J. Strength Cond. Res. 2012, 26, 3366-3376. [CrossRef] [PubMed]

3. Bayios, I.A.; Anastasopoulou, E.M.; Sioudris, D.S.; Boudolos, K.D. Relationship between isokinetic strength of the internal and external shoulder rotators and ball velocity in team handball. J. Sports Med. Phys. Fit. 2001, 41, 229-235.

4. Chelly, M.S.; Ghenem, M.A.; Abid, K.; Hermassi, S.; Tabka, Z.; Shephard, R.J. Effects of in-season short-term plyometric training program on leg power, jump- and sprint performance of soccer players. J. Strength Cond. Res. 2010, 24, 2670-2676. [CrossRef] [PubMed]

5. Ortega-Becerra, M.; Pareja-Blanco, F.; Jimenez-Reyes, P.; Cuadrado-Penafiel, V.; Gonzalez-Badillo, J.J. Determinant Factors of Physical Performance and Specific Throwing in Handball Players of Different Ages. J. Strength Cond. Res. 2018, 32, $1778-1786$. [CrossRef]

6. Anderson, C.E.; Sforzo, G.A.; Sigg, J.A. The effects of combining elastic and free weight resistance on strength and power in athletes. J. Strength Cond. Res. 2008, 22, 567-574. [CrossRef]

7. Bellar, D.M.; Muller, M.D.; Barkley, J.E.; Kim, C.H.; Ida, K.; Ryan, E.J.; Bliss, M.V.; Glickman, E.L. The effects of combined elasticand free-weight tension vs. free-weight tension on one-repetition maximum strength in the bench press. J. Strength Cond. Res. 2011, 25, 459-463. [CrossRef] 
8. Joy, J.M.; Lowery, R.P.; Oliveira de Souza, E.; Wilson, J.M. Elastic Bands as a Component of Periodized Resistance Training. J. Strength Cond. Res. 2016, 30, 2100-2106. [CrossRef]

9. Rhea, M.R.; Kenn, J.G.; Dermody, B.M. Alterations in speed of squat movement and the use of accommodated resistance among college athletes training for power. J. Strength Cond. Res. 2009, 23, 2645-2650. [CrossRef]

10. Schabort, E.J.; Hopkins, W.G.; Hawley, J.A. Reproducibility of self-paced treadmill performance of trained endurance runners. Int J. Sports Med. 1998, 19, 48-51. [CrossRef]

11. Ghigiarelli, J.J.; Nagle, E.F.; Gross, F.L.; Robertson, R.J.; Irrgang, J.J.; Myslinski, T. The effects of a 7-week heavy elastic band and weight chain program on upper-body strength and upper-body power in a sample of division 1-AA football players. J. Strength Cond. Res. 2009, 23, 756-764. [CrossRef] [PubMed]

12. McCurdy, K.; Langford, G.; Ernest, J.; Jenkerson, D.; Doscher, M. Comparison of chain- and plate-loaded bench press training on strength, joint pain, and muscle soreness in Division II baseball players. J. Strength Cond. Res. 2009, 23, 187-195. [CrossRef] [PubMed]

13. Lyttle, A.D.; Wilson, G.J.; Ostrowski, K.J. Enhancing Performance: Maximal Power vs. Combined Weights and Plyometrics Training. J. Strength Cond. Res. 1996, 10, 173-179. [CrossRef]

14. McBride, J.M.; Triplett-McBride, T.; Davie, A.; Newton, R.U. The effect of heavy- vs. light-load jump squats on the development of strength, power, and speed. J. Strength Cond. Res. 2002, 16, 75-82.

15. Markovic, S.; Mirkov, D.M.; Knezevic, O.M.; Jaric, S. Jump training with different loads: Effects on jumping performance and power output. Eur. J. Appl. Physiol. 2013, 113, 2511-2521. [CrossRef]

16. Paditsaeree, K.; Intiraporn, C.; Lawsirirat, C. Comparison Between the Effects of Combining Elastic and Free-Weight Resistance and Free-Weight Resistance on Force and Power Production. J. Strength Cond. Res. 2016, 30, 2713-2722. [CrossRef]

17. Shoepe, T.C.; Ramirez, D.A.; Rovetti, R.J.; Kohler, D.R.; Almstedt, H.C. The Effects of 24 weeks of Resistance Training with Simultaneous Elastic and Free Weight Loading on Muscular Performance of Novice Lifters. J. Hum. Kinet. 2011, $29,93-106$. [CrossRef]

18. McCurdy, K.; Langford, G.; Jenkerson, D.; Doscher, M. The validity and reliability of the 1RM bench press using chain-loaded resistance. J. Strength Cond. Res. 2008, 22, 678-683. [CrossRef]

19. Heckman, C.J.; Enoka, R.M. Motor unit. Compr. Physiol. 2012, 2, 2629-2682.

20. Soria-Gila, M.A.; Chirosa, I.J.; Bautista, I.J.; Baena, S.; Chirosa, L.J. Effects of Variable Resistance Training on Maximal Strength: A Meta-Analysis. J. Strength Cond. Res. 2015, 29, 3260-3270. [CrossRef]

21. Hermassi, S.; Gabbett, T.; Ingebrigtsen, J.; van den Tillaar, R. Effects of a Short-Term In-Season Plyometric Training Program on Repeated- Sprint Ability, Leg Power and Jump Performance of Elite Handball Players. Int. J. Sports Sci. Coach. 2014, 9, 1205-1216. [CrossRef]

22. Khlifa, R.; Aouadi, R.; Hermassi, S.; Chelly, M.S.; Jlid, M.C.; Hbacha, H.; Castagna, C. Effects of a plyometric training program with and without added load on jumping ability in basketball players. J. Strength Cond. Res. 2010, 24, 2955-2961. [CrossRef] [PubMed]

23. Womersley, J.; Durnin, J.V. An experimental study on variability of measurements of skinfold thickness on young adults. Hum. Biol. 1973, 45, 281-292. [PubMed]

24. Chelly, M.S.; Fathloun, M.; Cherif, N.; Ben Amar, M.; Tabka, Z.; Van Praagh, E. Effects of a back squat training program on leg power, jump, and sprint performances in junior soccer players. J. Strength Cond. Res. 2009, 23, 2241-2249. [CrossRef] [PubMed]

25. Batterham, A.M.; Hopkins, W.G. Making meaningful inferences about magnitudes. Int. J. Sports Physiol. Perform. $2006,1,50-57$. [CrossRef]

26. Vincent, W. Statistics in Kinesiology; Human Kinetics: Champaign, IL, USA, 1995.

27. Hurlbert, S.; Levine, R.; Utts, J. Coup de Grâce for a Tough Old Bull: "Statistically Significant” Expires. Am. Stat. 2019, 73 , 352-357. [CrossRef]

28. Chelly, M.S.; Hermassi, S.; Aouadi, R.; Khalifa, R.; van den Tillaar, R.; Chamari, K.; Shephard, R.J. Match analysis of elite adolescent team handball players. J. Strength Cond. Res. 2011, 25, 2410-2417. [CrossRef]

29. Hermassi, S.; Chelly, M.S.; Fathloun, M.; Shephard, R.J. The effect of heavy- vs. moderate-load training on the development of strength, power, and throwing ball velocity in male handball players. J. Strength Cond. Res. 2010, 24, 2408-2418. [CrossRef]

30. Hermassi, S.; Chelly, M.S.; Tabka, Z.; Shephard, R.J.; Chamari, K. Effects of 8-week in-season upper and lower limb heavy resistance training on the peak power, throwing velocity, and sprint performance of elite male handball players. J. Strength Cond. Res. 2011, 25, 2424-2433. [CrossRef]

31. Schmidtbleicher, D. Training for power events. In Strength and Power in Sport; Komi, P.V., Ed.; Blackwell: London, UK, 1992; pp. 381-395.

32. Hedrick, A.; Anderson, J.C. The Vertical Jump: A Review of the Literature and a Team Case Study. J. Strength Cond. Res. 1996, 18, 7-12. [CrossRef]

33. Behrens, M.; Mau-Moeller, A.; Bruhn, S. Effect of plyometric training on neural and mechanical properties of the knee extensor muscles. Int. J. Sports Med. 2014, 35, 101-119. [CrossRef] [PubMed]

34. Aagaard, P.; Simonsen, E.B.; Andersen, J.L.; Magnusson, P.; Dyhre-Poulsen, P. Increased rate of force development and neural drive of human skeletal muscle following resistance training. J. Appl. Physiol. 2002, 93, 1318-1326. [CrossRef] [PubMed] 
35. Cormie, P.; McGuigan, M.R.; Newton, R.U. Developing maximal neuromuscular power: Part 1-biological basis of maximal power production. Sports Med. 2011, 41, 17-38. [CrossRef] [PubMed]

36. Behm, D.G.; Sale, D.G. Velocity Specificity of Resistance Training. Sports Med. 1993, 15, 374-388. [CrossRef] [PubMed]

37. Crewther, B.; Cronin, J.; Keogh, J. Possible stimuli for strength and power adaptation: Acute mechanical responses. Sports Med. 2005, 35, 967-989. [CrossRef]

38. Hermassi, S.; Wollny, R.; Schwesig, R.; Shephard, R.J.; Chelly, M.S. Effects of In-Season Circuit Training on Physical Abilities in Male Handball Players. J. Strength Cond. Res. 2019, 33, 944-957. [CrossRef]

39. Gorostiaga, E.M.; Granados, C.; Ibanez, J.; Gonzalez-Badillo, J.J.; Izquierdo, M. Effects of an entire season on physical fitness changes in elite male handball players. Med. Sci. Sports Exerc. 2006, 38, 357-366. [CrossRef]

40. Gorostiaga, E.M.; Granados, C.; Ibanez, J.; Izquierdo, M. Differences in physical fitness and throwing velocity among elite and amateur male handball players. Int. J. Sports Med. 2005, 26, 225-232. [CrossRef]

41. Granados, C.; Izquierdo, M.; Ibanez, J.; Bonnabau, H.; Gorostiaga, E.M. Differences in physical fitness and throwing velocity among elite and amateur female handball players. Int. J. Sports Med. 2007, 28, 860-867. [CrossRef]

42. Mascarin, N.C.; de Lira, C.A.B.; Vancini, R.L.; de Castro Pochini, A.; da Silva, A.C.; Dos Santos Andrade, M. Strength Training Using Elastic Bands: Improvement of Muscle Power and Throwing Performance in Young Female Handball Players. J. Sport Rehabil. 2017, 26, 245-252. [CrossRef]

43. Chelly, M.S.; Hermassi, S.; Shephard, R.J. Relationships between power and strength of the upper and lower limb muscles and throwing velocity in male handball players. J. Strength Cond. Res. 2010, 24, 1480-1487. [CrossRef] [PubMed] 